\title{
DISTRIBUTION IN SAR PALAEODOSES DUE TO SPATIAL HETEROGENIETY OF NATURAL BETA DOSE
}

\author{
NAVEEN CHAUHAN and ASHOK K. SINGHVI \\ Physical Research Laboratory, Navrangpura, Ahmedabad 380 009, India
}

Received 26 February 2010

Accepted 20 December 2010

\begin{abstract}
In luminescence dating of sediments, Mayya et al. (2006) pointed out that at single grain level, the beta dose for quartz grains is heterogeneous. This heterogeneity arises due the fact that the total potassium in sediment is contributed by few feldspar grains with up to $11-14 \%$ stoichiometric potassium (Huntley and Baril, 1997). Beta particles have a range of $\sim 2 \mathrm{~mm}$, which is comparable to grain sizes and inter-grain distances. This fact implies that the spatial fluctuation of beta emitters (Kfeldspars) around individual quartz grains results in heterogeneous dose deposition. These fluctuations therefore, lead to an inherent spread in palaeodoses received by individual quartz grains.

In this study, we compute the spread in single aliquot palaeodoses that arises exclusively due to heterogeneity in beta radiation dose received by individual grains. We thus postulate that 'single aliquots' (comprising several - typically 100 - heterogeneously irradiated single grains) would have an inherent spread in the palaeodose. In this work, we used Monte Carlo simulations to quantify the extent of spread in palaeodoses arising due to heterogeneity of beta dose and hence put a limit on the precision of age estimation. Simulations results indicated, that, 1) the average of the single aliquot palaeodoses provides the closest approximation to the true palaeodose, 2) the minimum number of aliquots that are needed to obtain a robust estimate of average palaeodose value depend upon desired precision and the concentration of $\mathrm{K}$, and 3 ) the ratio of maximum to minimum single aliquot palaeodose values for a given $\mathrm{K}$ concentration provides a measure of inherent spread arising due to beta dose heterogeneity. Any spread over and above this range, can be ascribed to other sources such as heterogeneous bleaching and sensitivity changes. Radiation dose from other uniformly distributed sources of beta particles ( $\mathrm{U}, \mathrm{Th}$ and $\mathrm{Rb}$ ) however would reduce this spread.
\end{abstract}

Keywords: Optical dating, sediments, beta dose, dose-rate, quartz, feldspars, Monte-Carlo Simulations.

\section{INTRODUCTION}

In luminescence dating of sediments, the Single Aliquot Regeneration (SAR) protocol permits palaeodose measurement using single grains and single aliquots (having several grains), (Murray and Wintle, 2000; Singhvi et al., 2011). Several aliquots/grains of a given sample are analyzed to obtain a statistically rigorous palaeodose.

Corresponding author: N. Chauhan

e-mail: chauhan@prl.res.in
Ideally if sample is well bleached then all the aliquots should give identical palaeodose values, however, it is observed that even for well-bleached samples, the palaeodoses obtained from different aliquots often exhibit higher than expected spread (Morthekai, 2007). This issue of high spread has been examined by Arnold and Roberts (2009), Bailey (2002), Morthekai (2007) and Roberts et al. (1998). Suggestion on possible causes included, complex pre- and post- depositional history (e.g. partial bleaching; mixing of grains from different sedi- 
ment layers); grain dependent sensitivity change during the preheat and read out; complexities in growth curve due to varied dose response of different luminescence components of OSL decay; etc. Statistical protocols have been devised to extract a realistic palaeodose from a set of palaeodoses. The choice of the analysis protocol is dictated by the nature of spread in palaeodoses (e.g. Galbraith, 1990; Juyal et al., 2006).

Mayya et al., (2006) quantified the dose distribution in individual quartz grains due to spatial fluctuation of ${ }^{40} \mathrm{~K}$ beta emitters (K-feldspar) in sediment matrix by developing a statistical basis to compute the spread in palaeodose derived using single grains of quartz. The study indicated that these fluctuations lead to a positively skewed spread in palaeodoses. Therefore, it is expected that single aliquots comprising such single grains would also have an inherent spread in palaeodoses. The current study quantifies the spread in single aliquot palaeodoses arising exclusively due to heterogeneous distribution of beta emitters and computes,

1) the amount of spread in palaeodoses of single aliquots.

2) minimum number of aliquots required for a robust estimation of palaeodose and estimates associated maximum possible expected error.

3) the maximum spread in mean of palaeodose distribution of aliquots due to fluctuation in the spatial distribution of beta emitters.

4) ratio of maximum to minimum palaeodoses, which can be used to identify the spread in palaeodoses that arises exclusively due to spatial fluctuation of beta emitters, such that any spread beyond this can be attributed to other factors such as incomplete bleaching and sensitivity changes (Galbraith, 1990; Singhvi et al., 2011).

In the following, we quantify the spread in palaeodoses using statistical parameters such as mean, standard deviation and the ratio of minimum to maximum value.

\section{THE MODEL}

To simulate the spread in single aliquot palaeodoses, single grain probability density functions $(f(x))$ were computed for variable $\mathrm{K}$ concentrations, using the prescription of Mayya et al. (2006). Fig. 1a shows $f(x)$ for $1 \% \mathrm{~K}$. Here, $x$ is the scaled dose (ratio of the palaeodose and the average dose). Treating $x$ as a random variable, single grain doses were randomly sampled from this distribution using inverse transformation method (Bevington and Robinson, 2003). In this method, the Cumulative Probability Distribution Function (CDF ' $r=F(x)$ ') for a random variable $x$ can be obtained from the probability density function $f(x)$,

$$
r=F(x)=\frac{\int_{-\infty}^{x} f(x) d x}{\int_{-\infty}^{+\infty} f(x) d x}
$$

$F(x)$ was normalized with respect to the total area of density function (varying from $-\infty$ to $+\infty$ ), and thus $r$ is
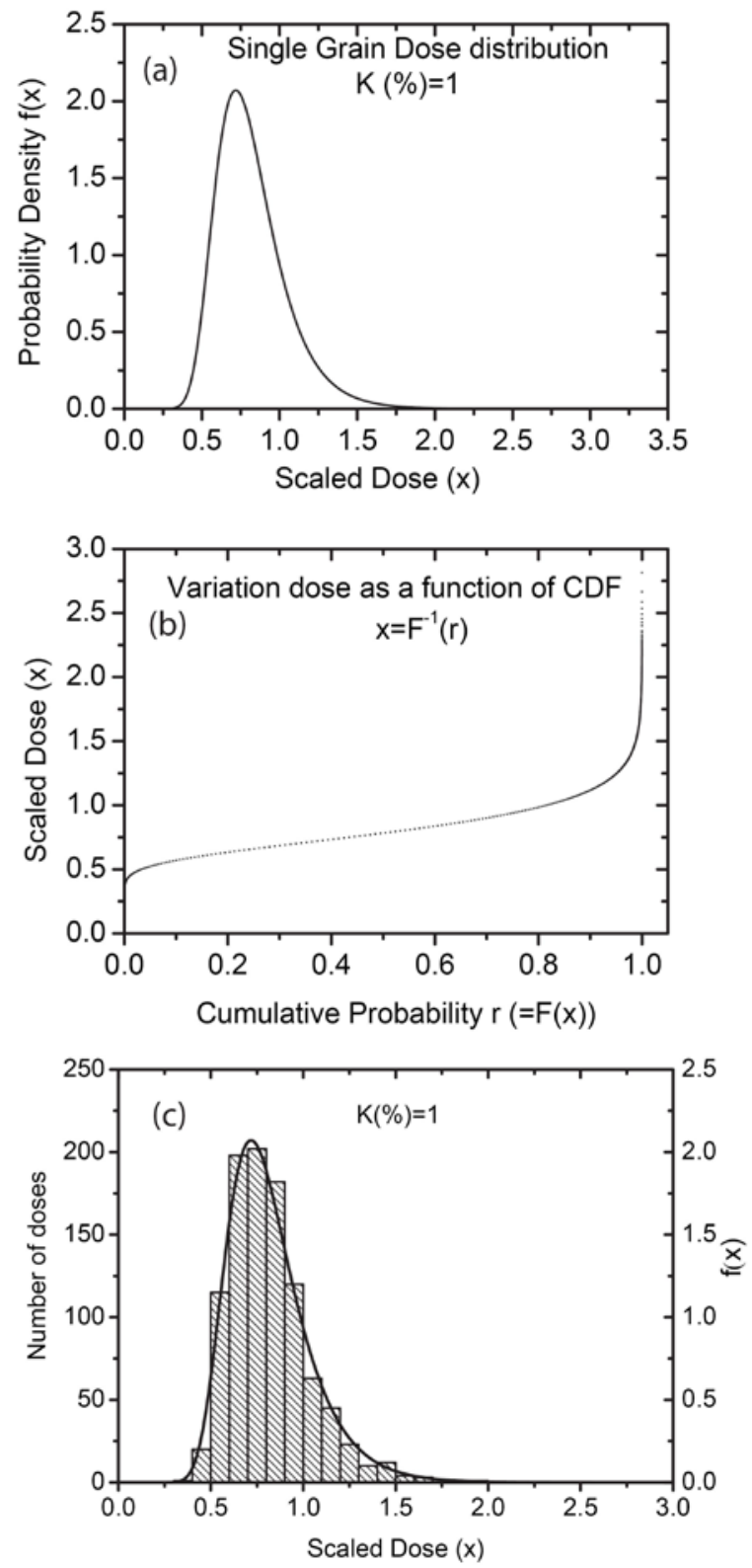

Fig. 1. (a) Single grain dose distribution computed using the method given by Mayya et al. (2006) for $1 \%$ K. (b) plot of scaled dose ' $x$ ' vs. ' $\mathrm{r}[=\mathrm{F}(\mathrm{x})]$ '. (c) The histogram of randomly generated palaeodose distribution for 1000 single grains and the corresponding theoretical single grain palaeodose distribution function. 
a uniform random variable in the range between 0 and 1. In this formalism $x$ is an independent random variable and $r$ is dependent variable. Inverse transformation of Eq. 2.1 holds with $r$ as an independent random variable with values between 0 and 1 and $x$ as dependent variable, i.e.

$$
x=F^{-1}(r)
$$

Fig. $1 \mathrm{~b}$ shows the graph of $x$ vs. $r$. Further, for a given random value $r$ the value of $x$ was calculated using (2.2), where $F^{-1}$ values were interpolated by a $3^{\text {rd }}$ order polynomial. Mathematica 5.1 was used for carrying out the computations and all Monte-Carlo simulations.

The uniform random number $r$ was generated from 0 to 0.9999 using function 'Random' available in the Mathematica 5.1. The 'Random' function uses Marsaglia|Zaman subtract-with-borrow generator for generation of random numbers. These random generators have period of $10^{200}$ to $10^{500}$ and are detailed in http://www.mathcom.com/corpdir/techinfo.mdir/q210.htm l\#q210.6.2.

Each generated random dose corresponds to a probable single grain palaeodose. Fig. 1c shows the distribution of randomly generated palaeodoses for 1000 single grains, and compares these with the corresponding theoretical dose distribution function.

In generating palaeodose for a single aliquot with several grains, the case of an aliquot comprising 100 single grains was considered. Given that in nature, typically about $5-10 \%$ grains contribute to the total luminescence light sum (Duller et al., 2000), and that the distribution of the bright grains in the multigrain aliquots is random, the number of bright grains for each aliquot was generated randomly by considering their number to vary from 0 to $10 \%$ of total number of grains. The palaeodose values for the single aliquot were then computed as the average of the palaeodoses that were generated for each of the aliquot with variable number of bright, randomly dosed grains. These results were analyzed for a variety of aspects as discussed below.

\section{NUMBER OF ALIQUOTS REQUIRED FOR PALAEODOSE ESTIMATION}

In SAR protocol, it is often difficult to determine the number of aliquots that should be measured for a reasonable approximation of palaeodose. Towards this, single aliquot palaeodoses for a large number of aliquots were computed using above methodology and procedure given in Fig. 2. To estimate the minimum number of aliquots, whose average palaeodose closely approximates the mean value of single grain palaeodose distribution; average palaeodose for a predefined number of randomly generated single aliquots was computed and tabulated for different ranges around the mean of single grain dose distribution. Fig. 3 (branch-I) provides the procedure followed. About 1000 different sets of single aliquot palaeodoses were generated for a fixed number of aliquots and average palaeodose was computed. Of these, sets lying within a range of $\pm 10 \%, \pm 5 \%$ and $\pm 1 \%$ of single grain mean palaeodoses were counted to obtain the probability of finding the average palaeodose within defined range of mean of single grain distribution. Fig. 4a shows the results for a typical case of $1 \% \mathrm{~K}$ which suggest that, to obtain average palaeodose value within $\pm 10 \%$ of the mean value of single grains average dose, 9 aliquots will be sufficient and for a $\pm 5 \%$ range about 35 aliquots are needed (here $95 \%$ probability is taken as the cut-off). For $\pm 1 \%$ range, $\sim 900$ aliquots would be needed. Given that this is impractical, a limit on the practically achievable precision is to be anticipated. As a reasonable compromise between the measurement time and the accuracy, the use of $\pm 5 \%$ range at $95 \%$ probability, 35 aliquots are needed for the case of $1 \% \mathrm{~K}$. This number will increase to 63 for $0.3 \% \mathrm{~K}$ and decrease to 24 for $3 \% \mathrm{~K}$ (Table 1; Fig. 4b).

Mayya et al., (2006) suggested that as the potassium concentration increases, the scatter in single grain palaeodose distribution decreases because the dose from Kfeldspar beta emitters becomes spatially homogeneous at single grain level and hence lesser number of aliquots are required. The data in Table $\mathbf{1}$ accord with this observation.

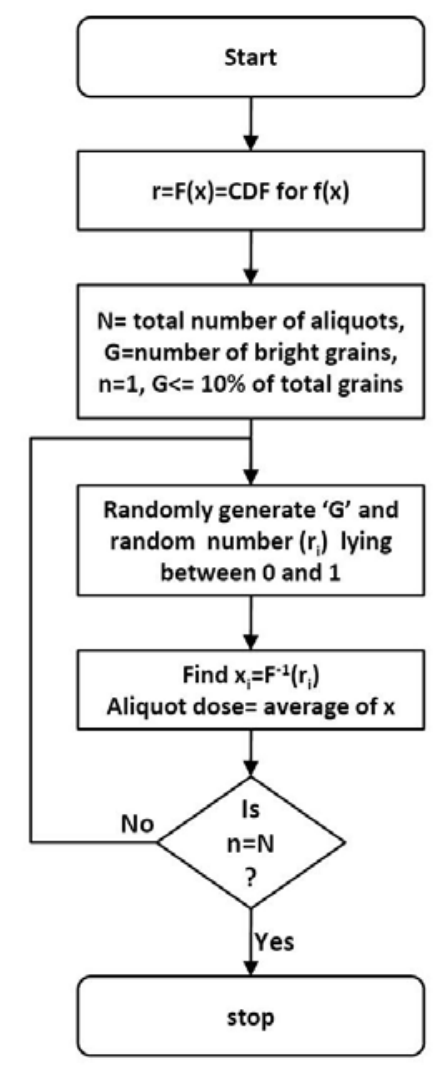

Fig. 2. Flow diagram showing the procedure followed to find the single aliquot doses for $N$ aliquots. 


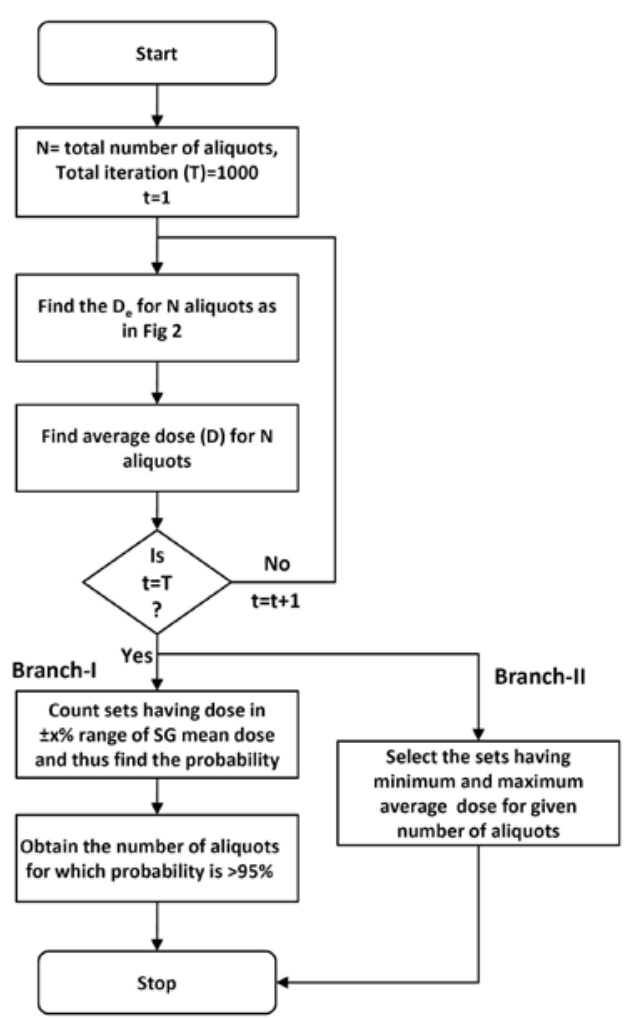

Fig. 3. Branch-l: procedure to generate 1000 different palaeodose set for $N$ aliquots and finding probability for having palaeodose values within a preset range of mean dose value. In this case, the ranges taken are $\pm 1 \%, \pm 5 \%, \pm 10 \%$. Branch-ll: It gives a method to find out the set maximum and minimum palaeodose values out of 1000 generated sets for a given number of aliquots.

Table 1. Number of aliquots required to obtain an estimate of dose value at different range limits for different concentrations.

\begin{tabular}{cccc}
\hline \multirow{2}{*}{$\mathrm{K}(\%)$ concentration } & \multicolumn{3}{c}{ Number of Aliquots Required } \\
\cline { 2 - 4 } & $\mathbf{\mathbf { 1 0 } \% \text { range }}$ & $\mathbf{\mathbf { 5 } \%}$ range & $\mathbf{\mathbf { 1 1 } \% \text { range }}$ \\
\hline 0.3 & 16 & 63 & $>1000$ \\
1 & 9 & 35 & $\sim 900$ \\
3 & 5 & 24 & $\sim 500$ \\
\hline
\end{tabular}

\section{VARIATION IN AVERAGE PALAEODOSE}

Discussion above shows that even for $95 \%$ probability of obtaining average palaeodose value within a particular range for given number of aliquots, there is always a $\sim 5 \%$ probability that palaeodose values would lie beyond the desired interval. We estimated the minimum and maximum average palaeodose values for given number of aliquots around the single grain mean palaeodose using the scheme given in Fig. 3 (branch-II). Typically, 1000 different sets of a pre-defined number of single aliquots were generated. Out of these, sets with maximum and minimum average palaeodose values were selected. Fig.
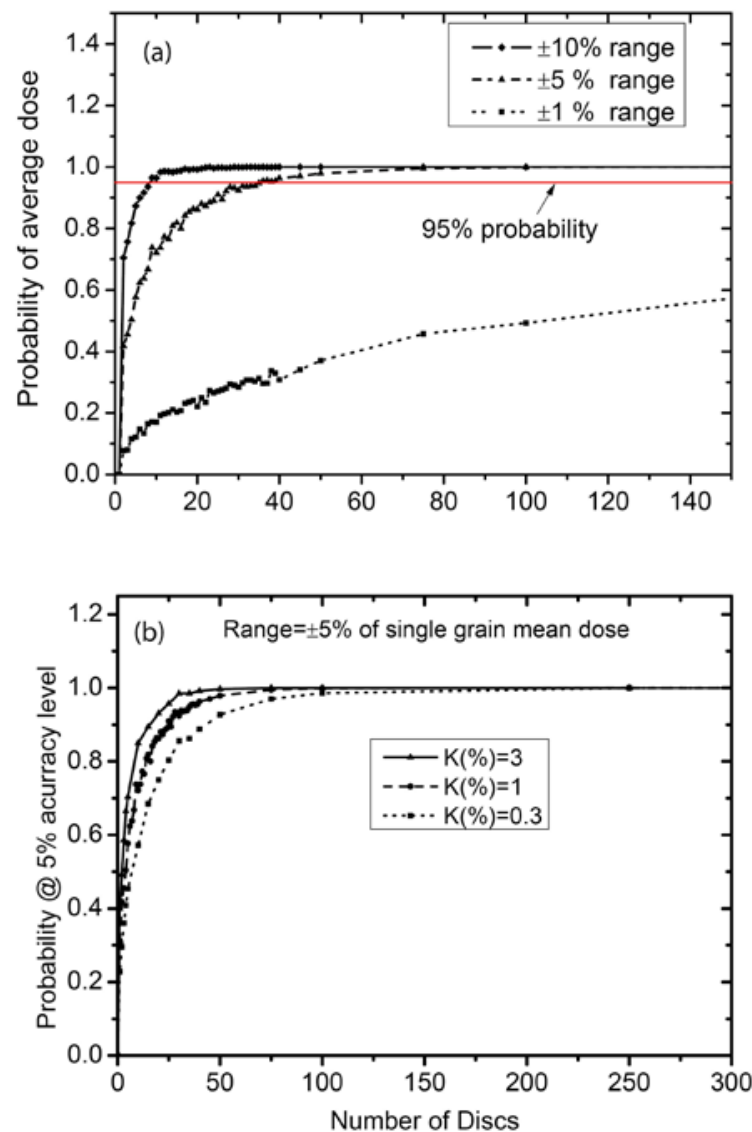

Fig. 4. (a) Variation of probability to obtain average dose within $\pm 1 \%$, $\pm 5 \%, \pm 10 \%$ range of mean of single grain palaeodoses for $1 \% \mathrm{~K}$. In this $95 \%$ probability is taken as a cut off to consider the number of aliquots suitable for dose evaluation, (b) shows the comparison for different $K$ concentration at aforementioned limits.

5a shows the variation of minimum and maximum average palaeodose values as a function of number of aliquots for $1 \% \mathrm{~K}$. As expected, an increase in the number of aliquots leads to a decrease in the maximum average dose value and increase in minimum average value. Both eventually converge to single grain mean dose.

The shaded region in Fig. 5a gives number of aliquots that have $>95 \%$ probability of having palaeodose within $\pm 5 \%$ range of the mean dose of single grains. Figs. 5b and $5 \mathbf{c}$ give the variation of maximum and minimum average dose values as a function of $\mathrm{K}$ concentration. As expected, the minimum and maximum average palaeodose value for $3 \% \mathrm{~K}$ concentration is close to the single grain mean palaeodose value. Importantly all the curves approach mean single grain dose asymptotically, suggesting that there has to be a trade off in terms of measurement time and marginal improvement in the precision. The maximum and minimum average dose values define the limit for the experimental precision that can be ex- 
pected. Table 2 provides associated maximum possible error $(\%)$ in estimating the palaeodose for different concentrations and at different range levels for suggested number of aliquots. This maximum possible error is calculated using the following relation,
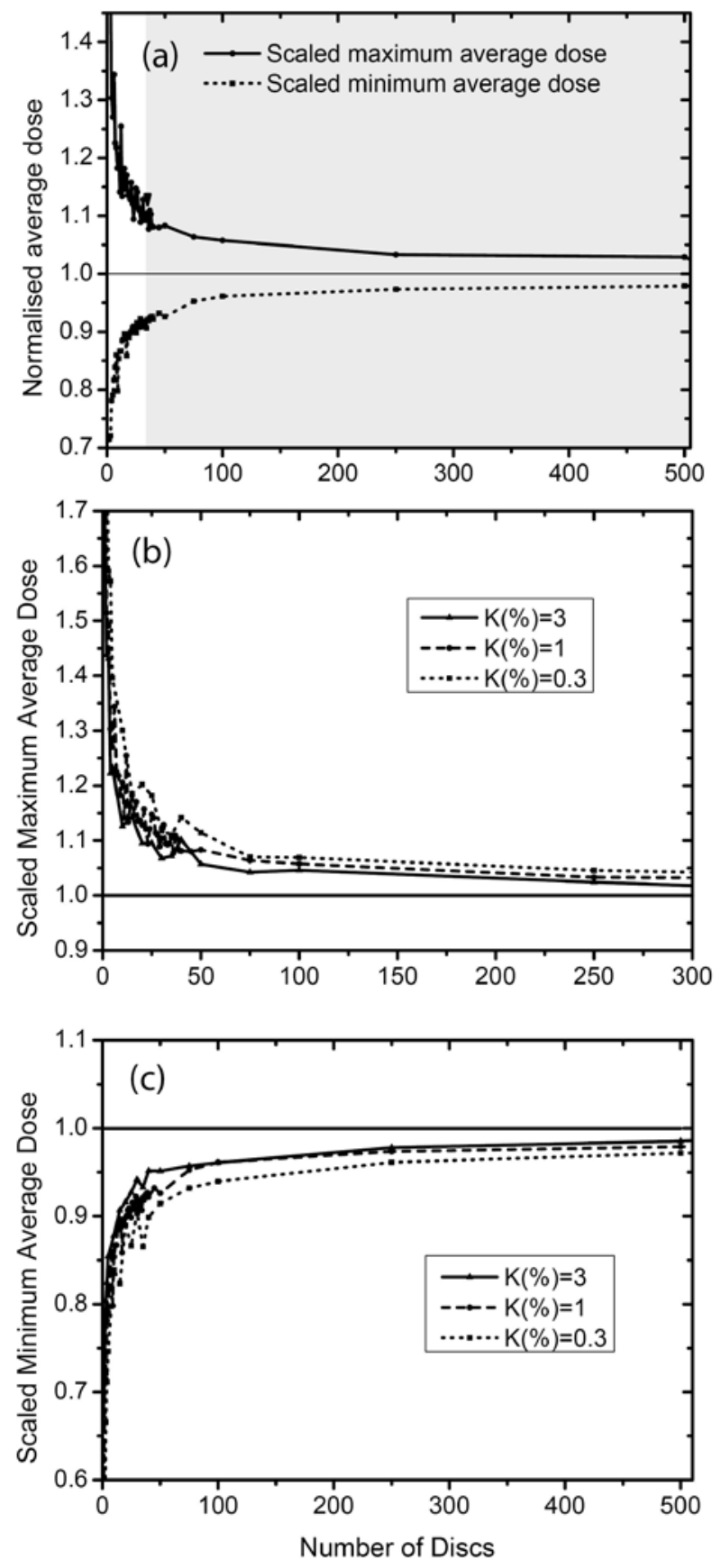

Fig. 5. (a) Variation of minimum and maximum average dose values as a function of number of aliquots for $1 \% \mathrm{~K}$. Shaded region gives the number of aliquots having $>95 \%$ probability for dose values lying within $\pm 5 \%$ of mean single grain palaeodose. (b) and (c) shows the comparison of minimum and maximum average dose values as a function number of aliquots for different concentrations.
Maximum possible error $(\%)=$ $\frac{\text { Maximum average dose }- \text { Minimum average dose }}{2(\text { average dose })} \times 100$

Table 2. Maximum possible error expected on the basis of beta dose heterogeneity model for different concentrations and different range limits.

\begin{tabular}{|c|c|c|c|}
\hline \multirow{2}{*}{$\mathrm{K}(\%)$ concentration } & \multicolumn{3}{|c|}{ Maximum possible error (\%) } \\
\hline & $\pm 10 \%$ range & $\pm 5 \%$ range & $\pm 1 \%$ range \\
\hline 0.3 & 18.1 & 8.5 & - \\
\hline 1 & 19.2 & 9.2 & 1.7 \\
\hline 3 & 19.0 & 8.4 & 1.5 \\
\hline
\end{tabular}

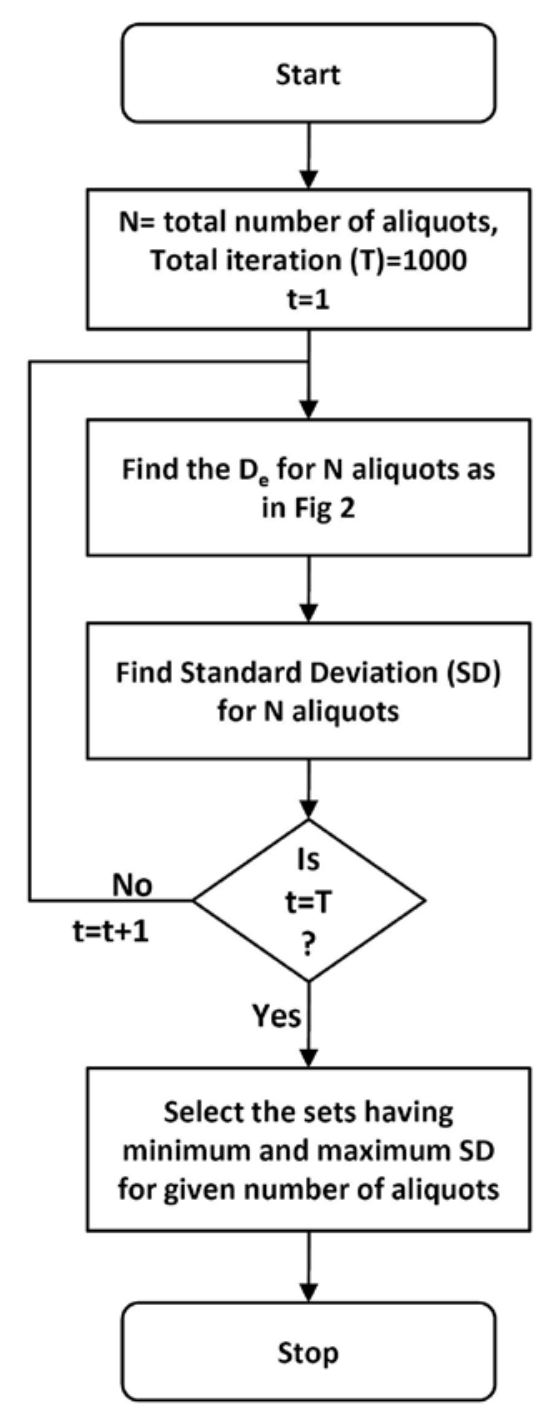

Fig. 6. Flow diagram showing the procedure to find the sets having maximum and minimum $S D$ value out of 1000 generated sets. 


\section{SPREAD IN THE PALAEODOSES}

To quantify the nature of spread in palaeodoses spread, so that spread beyond these theoretical limits could be justifiably ascribed to other causes like partial bleaching (e.g. Murray and Roberts, 1997), palaeodoses for 1000 different sets for a fixed number of single aliquots were simulated and standard deviations for each aliquot set was computed. Fig. 6 gives the flow diagram of the procedure. Fig. 7 shows typical histogram for the sets having maximum and minimum standard deviation (SD) for the case of a set comprising 35 aliquots. For uniformity, the scaled palaeodose values were divided into 10 bins from scaled dose of 0.5 to 2.2 .

Fig. 8a shows the variation of maximum and minimum SD as a function of number of aliquots. The result suggests that maximum standard deviation decreases with increase in number of aliquots and the minimum standard deviation increases and both asymptotically converge towards a common SD value of $\sim 0.15$ (for 1000 aliquots). This value as expected is lower as compared to the SD value of single grain distribution, which is $\sim 0.25$. A finite
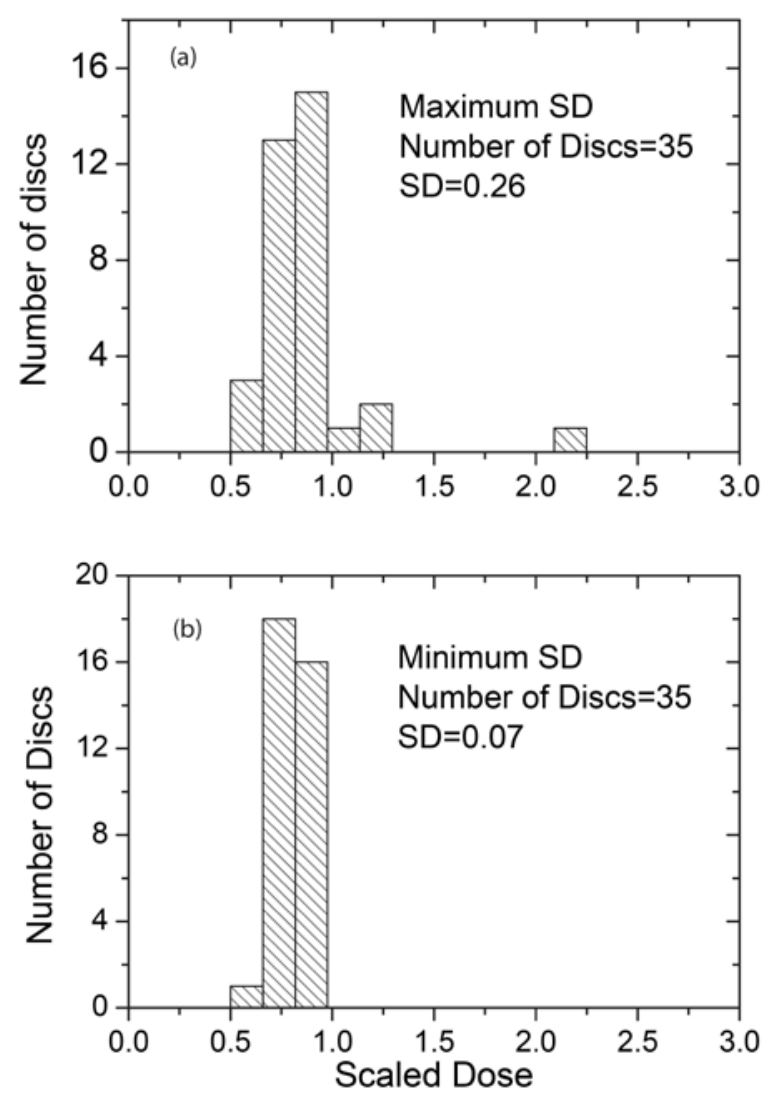

Fig. 7. (a) Dose histogram for the set of aliquots having maximum $S D$ value for different number of aliquots. (b) Dose histogram for sets having minimum $S D$ values.
SD for large number of aliquots indicates an inherent limit to the precision of single aliquot palaeodose. Other sources of scatter will add to this. Figs. 8b and $8 \mathrm{c}$ show the effect of the $\mathrm{K}$ concentration on the SD and as expected shows, SD is lower for higher concentration.

Generally, for a heterogeneously bleached sample, the minimum values from the spread of palaeodose are used to compute the age. However, it is equally likely that a
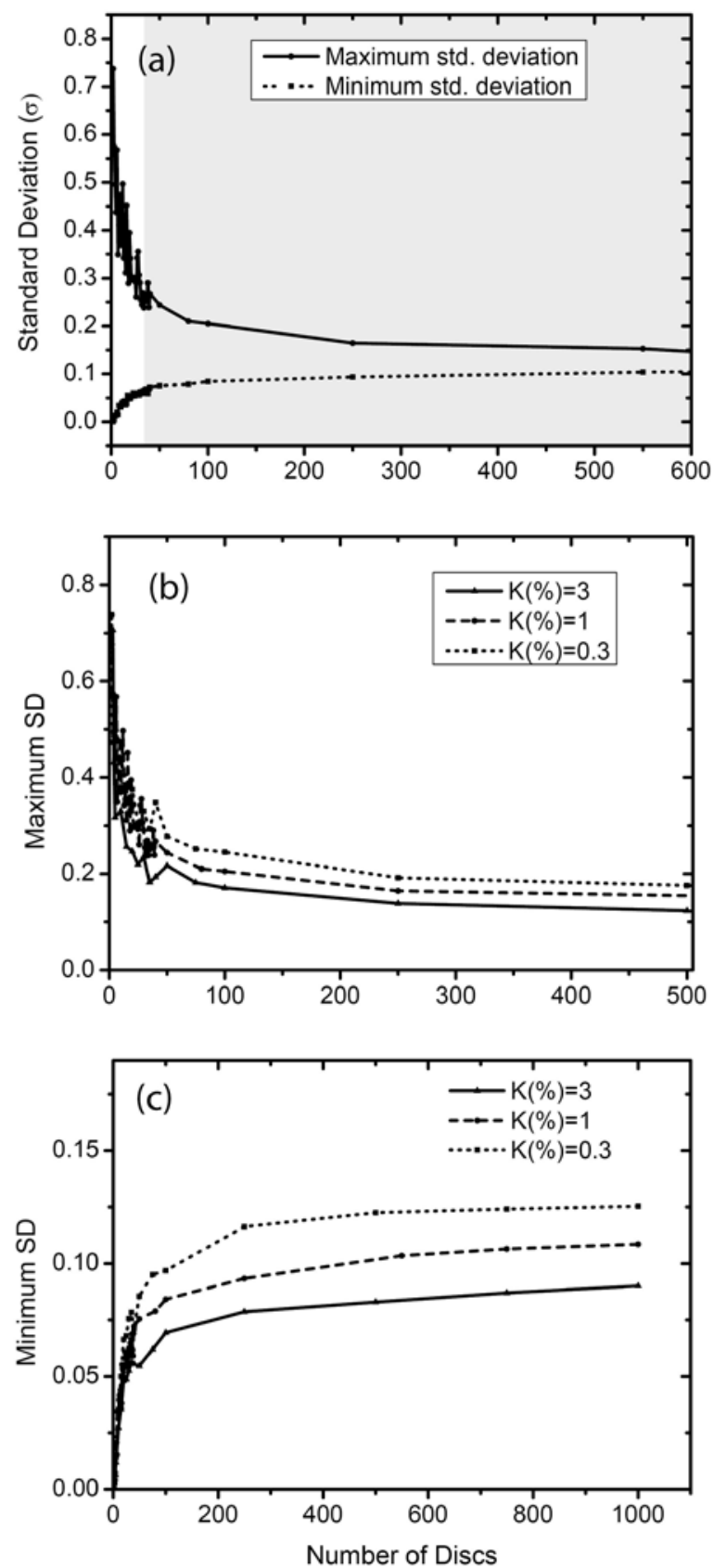

Fig. 8. (a) The variation of maximum and minimum standard deviation (SD) as a function of number of aliquots. (b) and (c) compares the same for different concentrations of $K$. 
well-bleached sample also mimics such a distribution due to dose heterogeneity. In such cases the use of minimum dose would lead to an underestimation, hence due care should be taken in analyzing such samples. The present practice of a decision on bleaching status of a sample is arrived at by an examination of the nature of the spread of palaeodoses on histogram or by the use of radial plot (Galbraith, 1988; 1990). Though necessary, these may not be sufficient and a way out will be to use the additional proxies and information derived from the analysis of modern analog of the deposition process, that can help in distinguishing sources of the distribution.

As an illustration of the inferences above, the case of 35 aliquots (with 100 grains and $\leq 10 \%$ of these contributing to the total light sum), from a sediment with $1 \% \mathrm{~K}$ content was considered and the palaeodoses were generated several times. Fig. 9 shows the nature of the spread for different sets. This suggests that the shape of palaeodose histogram may not be sufficient to decide the model to be used for palaeodose analysis.

For a sample with a palaeodose of $50 \mathrm{~Gy}$, the model generated minimum palaeodose is $\sim 17$ Gy and the maximum value is $\sim 152 \mathrm{~Gy}$. Since the spread is large, conventional wisdom would suggest that such a sample be considered as heterogeneously bleached and hence the use of standard protocols may lead to erroneous ages. The use of the ratio $(R)$ of the maximum and minimum palaeodose to account for the maximum possible variability due to beta dosimetry effects provide an additional check for cause of distribution. Based on a simulation of $10^{6}$ single aliquot palaeodose histories for $1 \% \mathrm{~K}$, the minimum-scaled palaeodose obtained is 0.31 and maximum palaeodose is 3.2 (i.e. $\mathrm{R} \sim 10$ ). Thus, ratio $\mathrm{R} \geq 10$ suggests that sources other than ${ }^{40} \mathrm{~K}$ are contributing to the spread in the palaeodoses. In natural samples, in addition to the heterogeneous beta dose contribution by ${ }^{40} \mathrm{~K}$, uniform dose by $\mathrm{U}$, Th and ${ }^{40} \mathrm{~K}$ gamma are also deposited. So while evaluating the ratio the contribution of this uniform dose need to be subtracted from the distribution.

\section{EXPERIMENTAL VERIFICATION}

To illustrate this further, we examine two samples; one from beach sand from E. Timor and the second was dune sand from the Niger in Sahara desert, Africa. Table 3 shows their U, Th and K concentrations. Fig. 10 shows the palaeodose histograms. To remove the contribution of the uniform dose, the minimum dose value of the distribution was considered to have contribution from heterogeneous beta dose and uniform dose. It was assumed that other sources leading to variable doses, did not contribute to the minimum dose. The fraction of uniform dose in the minimum dose value was evaluated using the respective dose rate fraction and was subtracted from all other dose values to get the palaeodoses distribution due to heterogeneous sources. The minimum dose value for the dune sand is 10.8 Gy while the maximum dose value is
Table 3. The concentration of radioactive elements for the two samples E. Timor beach sand and Sahara dune sand along with their respective $K$ beta dose fraction.

\begin{tabular}{lcc}
\hline Isotope & $\begin{array}{c}\text { Beach Sand from } \\
\text { E.Timor }\end{array}$ & $\begin{array}{c}\text { Dune sands from } \\
\text { Sahara }\end{array}$ \\
\hline Uranium $(\mathrm{ppm})$ & $0.68 \pm 0.08$ & $0.6 \pm 0.2$ \\
Thorium $(\mathrm{ppm})$ & $2.94 \pm 0.23$ & $0.40 \pm 0.04$ \\
Potassium $(\%)$ & $0.71 \pm 0.05$ & $0.14 \pm 0.01$ \\
Fraction of K beta dose & $\sim 40 \%$ & $\sim 22 \%$ \\
\hline
\end{tabular}

12.4 Gy. After removing the contribution due to uniform component the value changes to $2.37 \mathrm{~Gy}$ and $3.98 \mathrm{~Gy}$ and hence the ratio is 1.7 suggesting that, the sample has the spread in palaeodoses only because of the beta heterogeneity and hence the average value of the doses should provide accurate results. Adopting similar methodology for the beach sand, it is found that the maximum and minimum doses after removing uniform dose component are $1.38 \mathrm{~Gy}$ and $21.2 \mathrm{~Gy}$ and hence ratio, is 19.8. This clearly indicates that the sample has other sources of distribution in addition to the beta heterogeneity and appropriate model need to be applied. Thus, we find that the spread in single aliquot palaeodoses can be predicted based on beta heterogeneity concept and proper analysis protocol can be then selected using ratio of maximum and minimum doses along with the dose histogram and radial plot.

\section{DISCUSSION}

Heterogeneity in the palaeodose due to spatial fluctuation of the beta sources around different quartz grains results in distribution in single aliquot palaeodoses. It is inferred that, the average palaeodose of a distribution gives a realistic estimate of the palaeodose irrespective of the nature of variability in palaeodose distribution if beta heterogeneity is the sole cause of variation. Aspects like minimum number of aliquots required for realistic palaeodose values, convergence of maximum and minimum average dose values and SD values, anomalously high palaeodose values, etc. can be explained on the basis of fluctuations in dose in single grains.

However, this study presents the case when only $\mathrm{K}$ sources are heterogeneously distributed in the sediment matrix. As in nature, other radioactive sources, which are generally uniformly distributed, also contribute to the beta and gamma dose. For the case of simultaneous presence of both the components, the distribution in doses gets affected by the uniform component, which dilutes the scatter in the single aliquot dose distribution. This uniform component needs to be subtracted to infer the extent of spread due to heterogeneous K - beta dose.

Occasionally it is found that in palaeodose histogram or radial plot, some of the palaeodose values are anomalously higher than rest of the palaeodose values. These palaeodoses are attributed to the presence of some zircon 

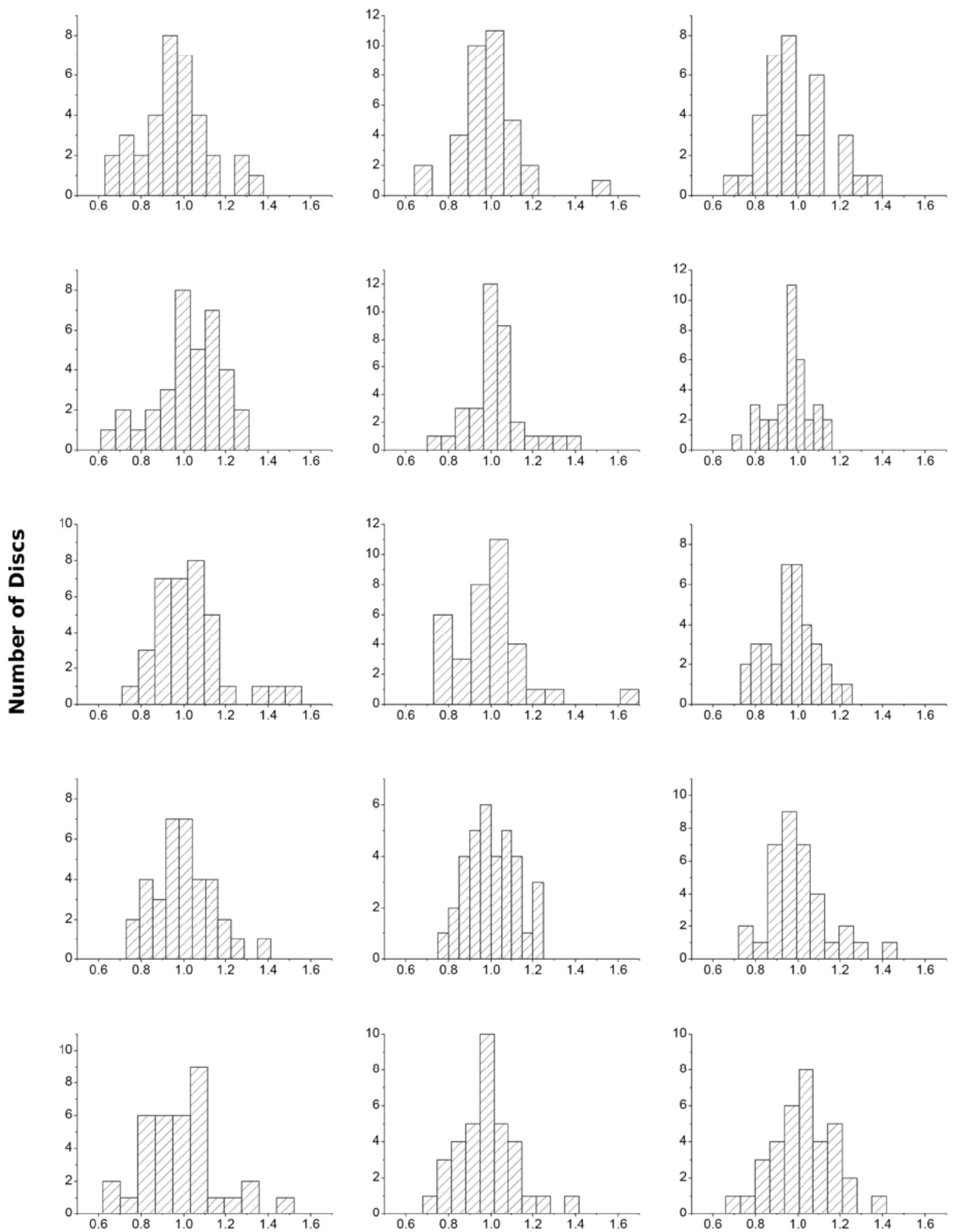

Scaled Dose

Fig. 9. The variation in shapes of dose histogram obtained for set of 35 aliquots for a concentration of $1 \% \mathrm{~K}$. 

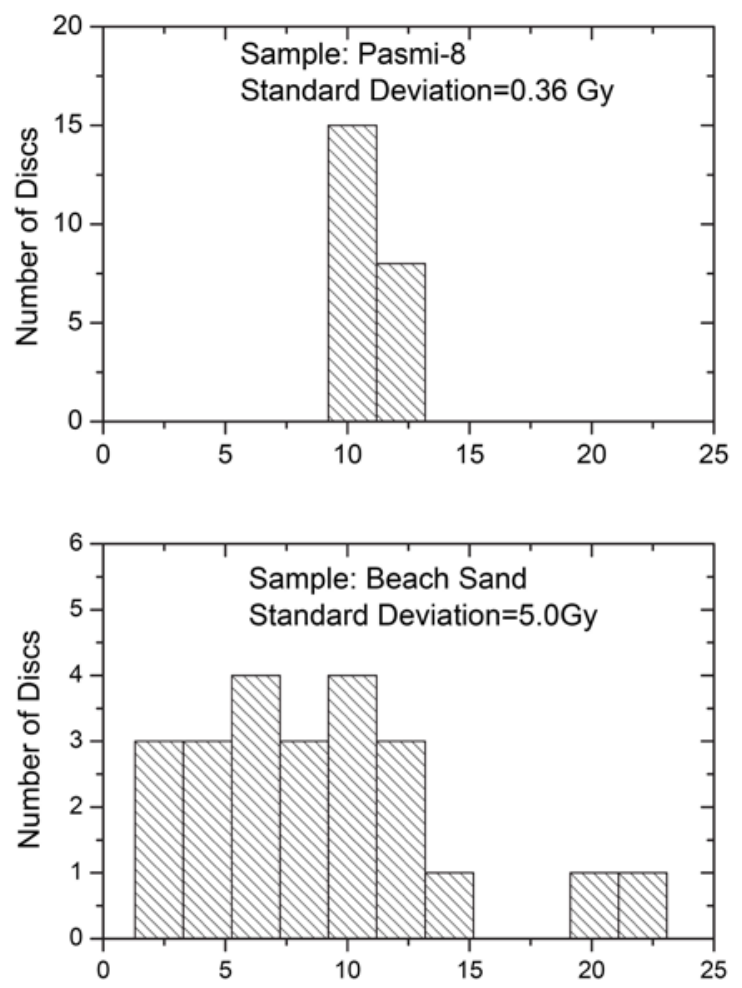

Equivalent Dose (Gy)

Fig. 10. Dose histograms obtained for the samples from two different natural conditions. (a) From dune sand from Sahara desert (b) Beach sand from Australia.

or highly radioactive grains (McFee and Tite, 1998) present in vicinity of quartz grains, as these grains receive a higher palaeodose values. This study suggests that anomalously high doses can also arise on account of heterogeneous beta dose deposition as shown in Figs. 7 and 9.

\section{CONCLUSIONS}

The present analysis permits following inferences,

1) Beta dose heterogeneity perhaps can cause a large spread in palaeodoses and hence bleaching heterogeneity need not always be implicated. This presents a paradigm shift from the conventional considerations so far. Also it implies that when other sources of variability are not present, average value of the dose distribution provides more realistic estimate of the palaeodose irrespective of the shape of distribution.

2) The spread in palaeodose places a limit on the precision of single aliquot measurements and typically, about 35 aliquots are needed for a palaeodose value within $\pm 5 \%$ of the mean of single grain value. It is suggested that number of aliquots at $\pm 1 \%$ accuracy limit would need analysis of about $\sim 900$ aliquots.

3) The distribution of doses on histogram or radial plot may not be sufficient to predict the source of variability. However the use of ratio of maximum to minimum beta dose due to ${ }^{40} \mathrm{~K}$ can be used as an additional proxy for identifying nature of variablity.

4) If ratio of maximum to minimum beta dose of ${ }^{40} \mathrm{~K}$ dose value is more than 10 , then factors other than beta source fluctuations are responsible for variation in doses.

5) Heterogeneity of beta dose, can also lead to anomalously high palaeodose. These are at times ascribed to the presence of zircon grains with high internal radioactivity and associated beta dose.

\section{REFERENCES}

Arnold LJ and Roberts RG, 2009. Stochastic modelling of multi-grain equivalent dose $\left(D_{\mathrm{e}}\right)$ distributions: Implications for OSL dating of sediment mixtures Quaternary Geochronology 4(3): 204-230, DOI $10.1016 /$ j.quageo.2008.12.001

Bailey R, 2002. Simulations of variability in the luminescence characteristics of natural quartz and its implications for estimates of absorbed dose Radiation Protection Dosimetry 100(1-4): 33-38.

Bevington PR and Robinson DK, 2003. Data reduction and error analysis for the physical sciences. Mcgraw-Hill, New York, $3^{\text {rd }}: 336 \mathrm{pp}$.

Duller GAT, Bøtter-Jensen L and Murray AS, 2000. Optical dating of single sand-sized grains of quartz: Sources of variability Radiation Measurements 32(5-6): 453-457, DOI 10.1016/S13504487(00)00055-X.

Galbraith RF, 1988. Graphical display of estimates having differing standard errors Technometrics 30(3): 271-281.

Galbraith RF, 1990. Radial plots: Graphical assessment of spread in ages Nuclear Tracks and Radiation Measurements 17(3): 207-214, DOI 10.1016/1359-0189(90)90036-W.

Huntley DJ and Baril MR, 1997. The K content of K-feldspars being measured in optical dating or in thermoluminescence dating. Ancient TL 15(1): 11.

Juyal N, Chamyal LS, Bhandari S, Bhushan R and Singhvi AK, 2006. Continental record of the southwest monsoon during the last 130 ka: Evidence from the southern margin of the Thar desert, India Quaternary Science Reviews 25(19-20): 2632-2650, DOI 10.1016/j.quascirev.2005.07.020.

Mayya YS, Morthekai P, Murari MK and Singhvi AK, 2006. Towards quantifying beta microdosimetric effects in single-grain quartz dose distribution Radiation Measurements 41(7-8): 1032-1039, DOI 10.1016/j.radmeas.2006.08.004.

McFee CJ and Tite MS, 1998. Luminescence dating of sediments-the detection of high equivalent dose grains using an imaging photon detector Archaeometry 40(1): 153-168, DOI 10.1111/j.14754754.1998.tb00830.x.

Morthekai P, 2007. Investigations on radiation dose distribution in natural environment and their implications in luminescence chronology. Unpublished Thesis, Gujarat University.

Murray AS and Roberts RG, 1997. Determining the burial time of single grains of quartz using optically stimulated luminescence Earth and Planetary Science Letters 152(1-4): 163-180, DOI 10.1016/S0012-821X(97)00150-7.

Murray AS and Wintle AG, 2000. Luminescence dating of quartz using an improved single-aliquot regenerative-dose protocol Radiation Measurements 32(1): 57-73, DOI 10.1016/S1350-4487(99)00253-X.

Roberts R, Bird M, Olley J, Galbraith R, Lawson E, Laslett G, Yoshida H, Jones R, Fullagar R, Jacobsen G and Hua Q, 1998. Optical and radiocarbon dating at jinmium rock shelter in northern Australia. Nature 393(6683): 358-362, DOI 10.1038/30718.

Singhvi AK, Stokes S, Chauhan N, Nagar YC and Jaiswal M, 2011. Changes in natural OSL sensitivity during single aliquot regeneration procedure and their implications for equivalent dose determination Geochronometria 38(3): 231-241, DOI 10.2478/s13386011-0028-3. 